\title{
Study on the Effect of the Strategy of Chinese Literary Translation
}

\section{Liying Mi}

School of Foreign Studies, Shanghai University of Finance and Economics, Shanghai, P.R.China

\section{Email address:}

mi.liying@mail.shufe.edu.cn

\section{To cite this article:}

Liying Mi. Study on the Effect of the Strategy of Chinese Literary Translation. Science Innovation. Vol. 4, No. 6, 2016, pp. $247-252$. doi: 10.11648/j.si.20160406.11

Received: September 26, 2016; Accepted: November 22, 2016; Published: December 1, 2016

\begin{abstract}
In order to enhance the national cultural soft power and international influence of Chinese culture in recent years, the government increased the pace of Chinese culture "going global". From the present situation, Chinese culture and literature have made some achievements in the process of "going global", but there are still some problems and challenges. In order to go global successfully, translation effect of Chinese culture and literature need to be put in the first place. Based on the present situation of the translation of Chinese literary works, this thesis analyzes the obstacles and the causes of Chinese literary translation, and puts forward the methods and strategies to improve the translation effect.
\end{abstract}

Keywords: The Effect of Translation, The Strategy of Translation, Culture Going Global

\section{中国文学外译的译介效果策略研究}

\author{
米丽英 \\ 外国语学院, 上海财经大学, 上海, 中国 \\ 邮箱 \\ mi.liying@mail.shufe.edu.cn
}

摘要: 政府为了增强国家文化软实力、中国文化国际影响力, 近年来加大了文化走出去的步伐。从现状来看, 中国文 化和文学作品, 在走出去的过程中取得了一定的成就, 但也存在一些问题、面临一些挑战。中国文化文学要想成功地 走出去, 就需要将译介效果放在首要位置。本文从中国文学作品的译出现状、面临的困境出发, 分析了对外译介存在 的障碍及其原因，提出了提高译介效果的方法与策略。

关键词: 译介效果, 译介策略, 文化输出

\section{1. 引言}

文化代表着一个国家与民族的软实力, 是意识形态吸 引力体现出来的力量, 它为一个国家树立国际形象、提升 国际影响力发挥着至关重要的作用。

在跨文化交际中, 国家之间的文化输出与输入在理论 上应该是一个对等的双向交流。一直以来, 中西跨文化双
向交流存在许多不对等的问题。由于各国经济水平、综合 国力的不均衡, 各种文化在国际交流有的处于强势, 有的 处于劣势, 地位差异较为明显。

回顾历史，在很长的一段时间里，中国在文化交流和 传播方面的 “译入” 与 “译出” 严重失衡。自清末民初而 
下, 外国文化大面积、大批量的译介走入中国, 繁荣并影 响着中国的学术和文化市场。

相较于 “引进来” 的丰富多样现状，中国文化 “走出 去” 的状况则显得十分萧条、惨淡, 造成了中国文化对外 译介明显失衡的状态 [1]。可见, 中国文化与文学作品在 走出去的过程中存在不少的困难和障碍, 中国文化在外国 市场仍处于边缘地位, 仍存在较大的文化赤字。要想改变 文化交流失衡严重的格局, 建立与国际社会之间平等、双 向的文化交流, 需要作出一系列的努力。

近年来, 随着中国经济的迅速发展与国际地位的不断 提高, 中国文学文化走向世界的重要性和迫切性也随之加 强。

基于这一需要, 中国政府已经将如何提高国家软实力 作为一项重要的课题来抓。中国的文学界、翻译界都在积 极探索中国文化 “如何走出去” 的途径。“走出去” 战略 的本质是在继续吸收外来优秀文化的同时, 转变以往吸收 多而输出少的局面, 形成双向、均衡交流和传播的新格局, 早日实现与西方的平等对话。

只是, 在涉及中国文化对外话语权的内容上, 我们仍 缺少权威的话语内容和传播渠道, 一定程度上影响了我们 文化话语权和对外传播的效力和能力。

另一方面, 对经典文学类作品的翻译, 我们有长进的 地方, 但是必须看到, 现在我们对经典中国文化了解的水 平总体上是有所下降的 [2]。

五千年文明的积淀，使得中国拥有丰富的文化资源， 如何将它盘活成为文化资本, 改变文化贸易严重逆差的现 状, 顺利实现中国文化话语权的 “逆袭” , 需要对中国文 学文化外译的译介效果策略进行深入分析。

现在很多学者都在强调文化主动地 “走出去”、“送 出去”, “送” 的目的, 其实一大半不在于发展自己的文 化, 而是增加国家影响力, 尤其是文化弱势的形势下, 以 文化力促进经济与政治力。这就是所谓提升与硬实力可以 相辅而成的软实力 $[3]$ 。

相对于代表国防力量和经济力量的硬实力, 文化软实 力是国家软实力的核心因素, 具有导向力、吸引力和效仿 力, 能够影响人们的精神风貌, 对人们的价值观产生积极 深远的影响。

由于中国文学作为中国文化的承载者进入国际市场, 意味着 “边缘文化” 去挑战西方 “主流文明”，文化上的 弱势决定了其文学作品接受度也较低。因此, 中国文学 “走出去” 的根本解决之道在于中华文化扩大其海外影 响力 [4]。

在中国译学界越来越重视中国文学对外译介与传播 的研究趋势中, 建立明确的翻译文化观, 在对自身民族文 化与异域文化充分了解与尊重的基础上, 建立起高度的文 化自觉, 以翻译促进跨文化交流, 让中国文化走向世界, 丰富世界文化 [5]。

文化软实力积淀着一个国家的精神高度, 是一个民族 保持永久生命力的源泉, 文化是具有经济属性的, 一国文 化的吸引力大小与经济吸引力大小呈正相关的关系。
随着中国在经济力量方面同发达国家的差距缩减, 如 何进一步提高代表国际竞争力的文化软实力、不断扩大文 化影响力, 如何将有内涵、有深度、有浓度的中国文化传 播出去, 此课题有着迫切而深远的重大意义。

顺应时代发展的需要, 中国政府为了增强国家文化软 实力、中国文化国际影响力, 近些年加大了文化走出去的 步伐。文学译介是文化交流最为重要的途径之一, 让中国 文学走出去的工作虽然取得了一些成绩, 但效果并不显著。 可见从边缘向中心的文化输出, 被接受的可能性会大大降 低, 困难仍然客观存在。

随着世界信息与文化全球化, 如何让中国文学更快更 好地走出国门, 精通本国语言, 熟知他国文化的翻译肩负 着向世界介绍、传播、弘扬中国文化的重要使命, 理应成 为中国文化对外输出的重要媒介。

\section{2. 翻译与文化输出}

译介学认为翻译就其外在作用而言, 是将一种语言信 息转化成另一种语言信息的行为。但就其本质而言, 是一 种跨文化的交际活动, 具有文化传播与移植的功能。黄友 义先生曾指出: “做翻译工作, 表面上看翻译的是文字, 实际上是在翻译文化, 是翻译文字背后深刻的思想 [6]。

可见, 翻译是一种跨语言、跨文化、跨社会的交际活 动, 可以说, 翻译因人类的信息传递、文化交流而存在, 是跨文化交流的重要桥梁, 对国家文化软实力的增长有着 举足轻重的作用。

人们都信奉“他山之石, 可以攻玉”。翻译历来所为, 正是搬运他山之石, 雕环本土之玉, 或反向往外搬运, 功 效亦然。越是 “民族的”, 越是世界的, 但只有通过翻译, 才能把 “民族的”，变成 “世界的”。要将中国文化推向 世界, 翻译是必经之路。

新中国60余年来, 我国翻译事业的成就超过了任何历 史时期, 翻译的语种大大增加、翻译的方式不拘一格、理 论的建树百花齐放、翻译的内容涉及各个方面。

时代在变迁, 王宁认为翻译在当今时代的一个重要作 用就在于对全球化时代的不同文化进行重新定位。在这方 面, 翻译一直在扮演着一个主导性的角色。他呼呼我国当 代翻译的重点应转向中译外, 从而使得翻译以一种积极的 姿态 “重新定位” 全球文化, 使中国文化能够真正屹立于 世界各国文化之中 [7]。

研究发现, 在中国对外的译介中, 译者起着决定性的 作用, 其对拟译文本的选择、翻译的策略与方法、译介的 文本质量, 在很大程度上决定了中国文学在接受国的再生 进程, 如美国的葛浩文、法国的杜特莱等译介各家的翻译, 就提供了最有说服力的证明 [8]。一个好的作家, 若能遇 到一个优秀的翻译家, 是他的幸运。

中国文化如何更好地走出去, 成为了文化界、文学界、 译学界乃至全社会普遍关心的热门话题。“世界文学就是 翻译”, 被视为最好的文化传播与推广方式之一的文学外 译受到各方的热切期待, 通过对中国文学作品的外译助力 中国文化顺利走出去是大家共同的愿望。 


\section{3. 文学外译取得的成绩和面临的困境}

\section{1. 文学外译取得的成就}

在中国的历史长河中, 从周朝开始设置译官, 此后涌现了几次翻译高潮, 优秀的翻译家百花争鸣, 翻译理论得以 不断完善与发展。表1对中国历史上出现的四次翻译高潮进行了简单的总结与归纳。

表1 中国历史上的四次翻译高潮。

\begin{tabular}{llll}
\hline 序号 & 时期 & 主要内容 & 主要成就 \\
\hline 第一次 & 东汉--唐宋 & 佛经翻译 & 将佛教引入国。 \\
第二次 & 明清 & 科技翻译 & 给中国带来了西方先进的科学技术。 \\
第三次 & 鸦片战争-- “五四” & 社科翻译 & 给中国人民带来了西方的自由主义精神, 尤其是马克思主义思想。 \\
第四次 & 改革开放--现在 & 全面翻译 & 全面地向中国呈现了世界其他国家的面貌, 中国的翻译研究逐步与国际接轨。 \\
\hline
\end{tabular}

其中，第一次翻译高潮为东汉至唐宋时期，翻译的主 要内容为佛经翻译; 第二次翻译高潮为明清两代, 主要为 西方科技类著作的翻译; 第三次翻译高潮为鸦片战争至 “五四” 运动时期, 翻译的主要内容为西学翻译; 改革开 放至今为第四次翻译高潮, 这一次翻译高潮, 涉猎的领域 之广, 从事的人数之众, 译著的数量之多, 都是前三次翻 译高潮无法比拟的 [9]。

随着中国经济与政治地位地不断提高, 提升中国文化 的国际影响力得到了前所未有的重视。大家开始重新审视 传统文化资源, 争取充分提炼中国特色文化话语, 早日实 现与西方文化的平等对话。“民族的才是世界的” , 中国 文化话语权的提升, 需立足本土文化, 充分展现其鲜明和 独特的属性。

中国政府近年来十分重视如何提升文化话语权这一 工作, 出台了一系列的鼓励政策并采取了一系列的措施, 实施了 “中国图书对外推广计划”、“中国文学百部精品 对外译介工程”、“中国文化著作翻译出版工程”、“中 国文学海外传播工程” 等一批重点项目 [10]。

《大中华文库》作为 “中国文化外译” 国家宏观文化 战略重要组成部分的这套书籍的出版, 引起了相关人士的 关注。这套书的图书选题 110 种, 包含了哲学思想类、文 学经典类、历史类经典、军事类经典中的代表作品, 得到 了众多学者、翻译工作者以及18家知名出版社的大力支持 [11]。经过出版社与编委会专家严格审核过的《大中华文 库》中的每一本书都代表了我国最高的出版水平与出版质 量。这一翻译出版活动将中国传统文化的精髓输出国门, 为中国文化的域外传播无疑起到了积极的促进作用。

\section{2. 文学外译面临的主要困境}

当前汉外翻译出版工作取得了可喜的成绩，但是也面 临一些困境, 存在许多诸如译作质量不高、译介和传播效 果不理想、外译人才缺乏等亟待解决的问题。整体而言, 中国文学在海外的影响力还很有限, 中国文学外译的译介 效果的提高任重而道远, 需要付出不懈的努力。

1) 译作质量不高

翻译不是简单的语言表达问题, 尤其是文学、哲学之 类复杂文本的翻译, 要求对原文的思想文化背景有相当深 入的了解。目前在对中国文学的译介中, 转译比较普遍, 对原著的精神与意蕴的忠实传达难以保证。在欧美一些国 家, 中国当代文学的翻译出版为商业利益所驱动, 一味迎
合读者趣味, 不尊重原作, 删改和删节较为严重, 原作的 完整性受到影响, 误导了读者。

2) 传播效果不理想

近年来, 中国文学作品在国际上译介的数量虽然有了 大幅度地增加, 但被翻译出去的图书的发行量及其产生的 影响仍然不理想。其主要原因在于国外主流出版机构少有 参与中国文学作品的译介与推广。

根据中国作家协会创作研究部理论处的李朝全的统 计 [12], 所搜集到的870余种译作中, 语种分布比较详细 的情况如下: “日文262种, 法文244种, 英文166种, 德 文56种, 荷兰文 30 种, 罗马尼亚文 13 种, 瑞典文和意大利 文各12种, 西班牙文、丹麦文、韩文各 11 种, 波兰文和匈 牙利文各 9 种, 葡萄牙文和捷克文各 4 种, 俄文、挪威文和 阿尔巴尼亚文各3种, 克罗地亚文、斯拉夫文和马来文各2 种, 斯洛文尼亚文、土耳其文、乌克兰文和世界语各1种。” 从图1所示的语种分布情况来看, 应该说分布还是比较广 的, 但各语种之间明显不平衡, 译介品种前三位的语种为 日文、法文和英文, 分别为 262 种, 244 种和166种。

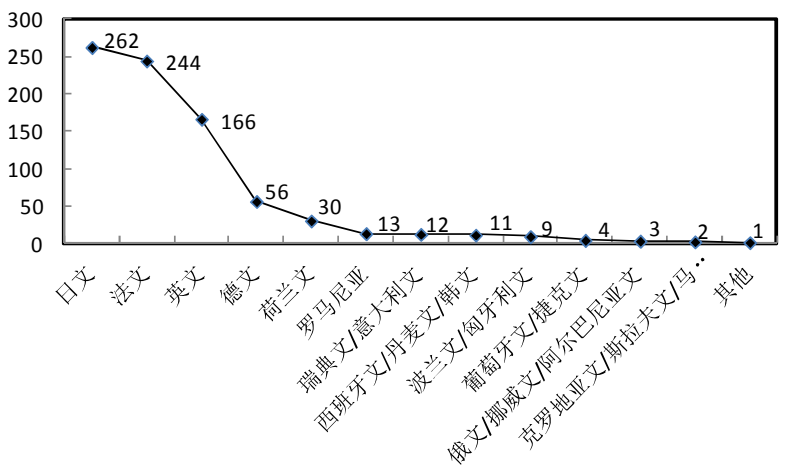

图1 870余种译作语种分布情况。

英语译介的中国当代文学作品数量之少, 值得我们深 思。根据美国史密斯大学的汉学家桑禀华教授的统计数据, 2009年美国翻译出版的文学图书有348种, 其中仅有8种来 自中国文学作品, 占美国的外国文学作品出版数量的 $4 \%$ [13]。国外有一些小的出版机构, 确实对中国当代文学的 翻译与出版感兴趣, 但由于资金有限, 很难有大的或系统 的翻译出版计划, 在很大程度上依赖于我国的出版资助, 在发行渠道方面也很少开拓, 长期以往, 有可能会形成恶 
性循环: 有资助就出版, 出版了也少有市场, 无法真正达 到文学作品译介对中外文化交流应该起到的促进作用。就 长远的发展和影响而言, 市场因素是我国对外译介所必须 考虑的。

3) 外译人才缺乏

译者翻译水平的高低直接影响原作的表现水准。莫言 作品的译者葛浩文先生被誉为 “西方首席汉语文学翻译 家”, 其译文地道流畅, 充分融合了西方读者的阅读习惯 与审美情趣, 同时又非常注重对作品所处的文化、社会及 历史背景的准确把握, 他对莫言荣获诺贝尔奖功不可没。 然而目前国内极度缺乏中译外的高端翻译人才, 据业内人 士估计, 国内具有中译外定稿水平的高级专家数量现今仅 有一二百人, 人才的贵乏直接导致了译文质量, 特别是近 年来粗制滥造现象不断呈现, 对中国文学的跨文化传播及 文化软实力的发展建设都产生了一定的负面影响。

\section{4. 加强中国文学外译的译介效果策略}

中国文学作品辐射面不广, 在海外普通受众中的影响 力仍然有待提高。美国弗吉尼亚大学汉学家罗福林 (Charles Laughlin) 曾说过: “在美国的大学图书馆里能 找到中国文学的英译本, 但是在美国图书市场上, 也就是 说主流的连锁书店, 基本上不会出现。”在美国, 很多美 国大学出版社出版的中国文学作品在商业市场是没有销 路的” [14]。中国文学作品在美国市场如此, 欧洲市场亦 然。

由此可见, 若普通受众的关注度不高, 自然会影响翻 译作品的销售量。要提高中国文学外译的译介效果, 需要 在译介内容、译介主体、译介途径等方面作出进一步的努 力。

\section{1. 科学选择译介内容}

在全球化背景下, 文化因素已上升至国际关系的中心 地位, 巧妙运用文化因素已成为提高国际竞争力与影响力 的重要途径。

从现状来看, 中国文化并非像其经济发展那样举世瞩 目, 为了更好地使中华文化顺利走出去, 我们首先需对自 己本国的文化所具有的价值有全面的了解。从博大精深灿 烂辉煌的中华文化中选择何种题材外译, 传统文化与现当 代文化的比例如何分配, 以及根据国外受众的价值观和所 处的社会环境、他们的品味和审美情趣, 分析到底什么样 的中国文学作品能够受到海外市场的欢迎与追捧等, 都是 值得我们关注的课题。

一般来说, 具有此特色的三类作品在国外比较受欢迎: 第一类: 世界性文学特色

著名作家余华、张爱玲、贾平凹等, 他们的作品很多 都已经翻译成西语。这类作品可以说是世界文学, 内容方 面可译性较强、受众比较广。

第二类: 反思与批判特色

带有反思、审视与批判色彩的作品, 西方读者希望通 过近现当代历史文化中的一些现象来关注中国或者个人 命运的变化, 如韩寒、莫言的作品等。
第三类：鲜明民族特色

以中国少数民族的文化、生活为表现题材的作品, 在 西方深受欢迎。少数民族鲜明的民族特色、物质和文化的 差异性和多样性、独特的风情风物包含着的独特鬼力应该 是吸引西方读者的原因所在。

可见，贴合海外受众的阅读期待和共有价值，选择具 有世界性的作品题材是翻译出版成功的前提。好的文学作 品, 仍然是传播一个国家的民族形象, 文化价值的最大的 推动力。我们要传播中国文化到海外, 一方面要重建文化 自信, 一方面也要懂得利用海外的认知图式, 作适当的取 舍与切割。

\section{2. 科学选择译介主体}

译者是发送文化信息的主体，对跨文化信息传播起着 关键性的作用。虽然中国文学一直致力于海外传播的尝试, 国家在政策层面也支持外译优秀的文学作品, 然而迄今为 止中国文学在 “走出去” 的历程中仍未取得实质性的突破 性进展。究其原因, 翻译在很大程度上成为制约“走出去” 的因素。

国际译联副主席、中国外文局副局长黄友义认为, “翻 译的最好办法就是中国人和外国人合作，中国作家想走出 去, 最好是选择外国人帮我们翻译, 然后由中国人来审核” [15]。

分析莫言作品日译、英译作品的译介效果而得到的启 示是: 若想追求文学作品在海外传播的最佳效果, 西方汉 学家群体仍然是最理想的译者。汉学家母语语言的语感, 显然比中国译者要强, 因此译介主体应该以像美籍汉学家 葛浩文、日本汉学家家吉田富夫、瑞典翻译家陈安娜等外 国译者为主, 可以辅以国内本土译者, 以便帮助国外译者 透彻地理解汉语以及其中所包含的文化内涵。

但是目前精通中国语言文化的海外汉学家数量稀少, 如果单纯依赖于这一模式, 则会制约中国文学文化的海外 传播广度。高端 “中译外” 人才短缺这一问题是影响和制 约中国文化走出去的关键问题。中国文化能走出去多远, 能否改变文化 “引进来” 和 “走出去” 之间巨大的落差, 很大程度取决于是否拥有相当数量的高水平中译外人才。

随着中国文化 “走出去” 的需求不断加大, 如何能有 效地培养本土翻译人才, 让中国更好地走向世界成为一项 重要课题。“中译外” 高端人才培养, 形成中外专家优势 互补的想法得到了重视, 希望由此建立起中外翻译专家资 源共享、紧密合作的机制。相信国外汉学家和优秀的本土 译者的通力合作会让越来越多的作品进入海外读者的视 野。

\section{3. 建立译介受众反馈机制}

中国文化走出去已经上升为国家战略，但文化传播在 西方世界却面临着严峻的挑战, 其主要原因在于缺乏对受 众的充分了解和在译介过程中读者意识的缺失 [16]。而 受众虽说是信息传播的对象，是信息的接受者，但从来就 不是被动或静止地接收信息, 相反, 面对某个文学作品, 受众往往从自己原有的意见、观点和兴趣对信息进行取舍, 采取或者不采取某个预期行为。 
在经济学领域, 潜在消费者是指当前尚未购买或使用 某种商品, 但在将来的某一时间有可能转变为现实消费者 的人。生产经营企业应该把握这类消费者的消费心理, 他 们直接影响企业的产品生产方向和数量。

同样的道理, 译介受众也对中国文化提供的传播作品 起着直接的决定性的作用, 文化文学的交流应该着眼于能 真正影响普通人精神生活的层面。我们所推介的文学翻译 作品要符合海外受众的审美情趣与阅读期待, 若不能让大 众引起心灵的共鸣, 就不能获得所期待的效果。所以, 文 学译介要注意收集受众对作品的反馈信息, 建立高效的效 果评估反馈机制。只有建立了效果评估反馈机制，才有修 正和调整决策的科学依据, 才能从失败的案例中总结出成 功的可能性。

\section{4. 拓展译介途径}

近几年, 莫言荣膺诺贝尔文学奖、麦家作品被收入《企 我经典》, 这大大提升了文学界文化自信心。但是中国作 家的文学作品真正 “走出去了” 吗? 是否真正得到海外主 流文坛的认可、获得市场与读者青睐了? 其实中国文学大 部分没有进入海外大众的视野, 很多都是束之高阁于各地 高校的图书馆里, 仅仅供一些专家通过研究文学作品来研 究中国所用。

由此可见, 中国文学在 “走出去” 的过程中, 仍然步 履蹒跚, 在海外的影响仍然微乎其微。成功的特例并不能 掩盖中国作家在西方仍然处于边缘的现状, 高质量翻译的 紧缺与版权代理机制的滞后仍然是横亘在前的难题。为了 改善这种局面, 应采取由政府推动和支持, 以民间为主体, 开展行业协同、国际合作的方式, 加大力度拓展译介途径。

\section{4.1. 文学作品的出版发行}

1. 寻找合适的海外出版商

好的作品与译本得到了保障之后, 在此基础上, 译介 途径便成为制约传播效果的重要因素。一部优秀的文学作 品是否能够成功外译, 取决于是否能找到合适的海外出版 商。

文学版权输出应该走专业的路子, 在中国作家存在语 言障碍、不熟悉海外出版市场的情况下, 海外代理人是理 想的媒介。译者可以自己在海外聘请懂行的版权文学翻译 经纪人帮忙联系出版社出版自己的作品。文学翻译经纪人 必须既了解中国文学, 又了解国际市场, 和国际间的出版 机构有很好的合作背景, 他是适应国际惯例和顺应时代发 展的必然产物, 应是 “中华文化外译” 的强力推手。

谢天振教授认为出版机构对作品的传播起着很大的 作用, 建议由国外出版机构出版发行中国翻译文学作品, 因为由国内出版社出版的翻译作品, 不易进入译入语社会 传播系统 [17]。

2. 加强国内出版商的联动机制

在国外出版机构出版力度不高的情况下, 应该加强政 府管理部门、出版界、翻译界、学界的联动机制, 使涉及 译介的部门、机构、单位形成一个有机整体。同时, 国内 出版社也可以创建《联合出版、版权转让》的国际性网站, 采用中、英、法、德、日等多国文字宣传和推介国内的优
秀作品并转让版权, 创造与国外出版社合作出版中国文学 作品的机会。

2008年长江文艺出版社和企鹅出版集团以版权输出 形式合作出版了英文版《狼图腾》（Wolf Totem）。《狼 图腾》的火爆销售, 无疑是中国出版社与国外出版社合作 的一次成功典范。

3. 扩大办境外出版社的规模

如果具备足够的财力和人力的话, 还可以在现有的基 础上扩大在国外办出版社的规模, 为中国文学作品在海外 出版走出困境助一臂之力。

\section{4.2. 国家与金融机构的财力支助}

\section{1. 设立专项基金}

国家可设立专项基金对面向海外出版的图书以及翻 译费进行补贴; 资助国外汉学家积极开展翻译活动、出资 邀请国际级学者、翻译家来中国完成一个翻译项目; 建立 中译外翻译基地, 便于国外汉学家翻译家与国内专家学者 和作家共同切碰翻译技法, 以便双方掌握涉及中国或外国 特色表达的内涵元素, 为读者翻译出更多、更好的作品, 创造一些机制性的环境。

2. 建立良好的发展制度

国家通过建立良好的面向译者的制度环境, 对翻译事 业投入专项支持, 加强统筹规划, 在充分发挥市场活力的 同时, 充分激发人的积极性、创造性和能动性, 以译者本 身的潜力、动力、活力来推动翻译事业的发展, 争取早日 解决 “中译外” 在中国对外文化交流中的差距问题。

3. 金融机构出资资助

金融机构可出资资助杂志的信息检索系统与公众平 台运营; 顺应电子出版的时代需要, 为推出文学作品的“光 盘” 版与 “微信” 版提供资金支助。

\section{4.3. 民间企业的力量}

可收购国外的剧院, 在属于自己的海外剧场里, 将中 国的文学作品以话剧的形式进行表演宣传, 为中国文学文 化的国际化竞争搭建稳固的平台。

也可加大收购海外电视台的规模, 借此大力宣传中国 文学文化的精髓, 引起海外观众对中国的注意。

\section{4. 4. 创设多重媒介}

为了改善中国文化文学传播渠道单一、流通不畅的局 面, 可以充分利用新媒体技术, 便于以多元化的传播途径 来拓宽传播范围, 使中国文学文化在国际社会的发展中产 生一定的影响。

具体可以采用的途径有:

1）借用西方报刊杂志等大众传播媒介进行宣传、加强与 图书出版社发行专业期刊的联系;

2）书展集展示、宣传、交流合作、贸易销售于一体, 是 中国文学作品走出国门的重要平台, 可以增加其次数、 拓展其规模;

3) 对于出版社来说, 要扩大销量, 最为流行的操作模式 无疑就是 “影视书互动”。书籍的销量火爆, 改编成 影视的概率就大增; 影视的热播往往也能带来书市的 轰动效应 $[18]$; 
4) 随着互联网的迅猛发展, 网络传播也得到了飞速发展。 网络传播给我们的时代提供了最快捷、便利的传播方 式, 将文学作品以数字形式存咜在光盘等存咜介质上, 通过网络快速传播, 能高速地在世界范围内进行信息 传递和交流;

5) 数字图书阅读已成为一种新趋势, 电子书市场的竞争 愈演愈烈，以后电子书市场定会迎来一场 “世纪之 战”, 通过电子书销售平台, 也可以增加海外读者接 触到中国文学作品的机会。

中国文化要实现顺利走出去, 要有明确的战略组织和 实施机构。美国的对外文化传播职能虽然散落在 11 个不同 部门中, 但是国务院专门设立了一个 “教育和文化事务 局”，负责专门协调文化传播和推广事宜。而且美国的非 政府组织在文化推广和传播中也起到了非常重要的作用。 虽说中国近几年也加大了对外文化推广的力度和投入, 但 是并没有形成一个统一协调和监管的部门来统筹实施文 化走出去战略，也缺乏引导民间资本的有效措施 [19]。 我国文化 “走出去” 的模式和途径, 可以为一种 “政 府扶持、银企合作、企业经营、建设国际化流通渠道与传 播平台” 的市场化模式。中国文化外译是一项旷日持久、 考验耐心、检验智慧的文化事业, 只有通过不断完善公共 政策、创新传播方式和进一步的资源整合等一系列举措, 才能逐步提升文化产业的影响力与国际竞争力, 加快文化 “走出去” 的步伐。

\section{5. 结语}

中国文化文学若能在世界大舞台上绽放自己的光彩, 不但能丰富我们自己的精神世界, 也能拓展人类的文化空 间, 可谓居功厥伟。

在当今全球化的背景之下, 翻译可以担当推动中国文 学文化 “走出去” 、扩大中国国际影响力的 “软实力”。 中国文学能否顺利 “走出去”, 冊庸置疑, 翻译工作者的 创造性工作起着举足轻重的作用。正是因为有了他们这样 的劳动, 中国文学外译已经取得了一些可观的成绩, 当然, 也还存在许多亟待解决的问题。为了加强中国文学外译的 译介效果, 科学选择译介内容与译介主体, 建立译介受众 反馈机制, 通过各种媒介拓展译介途径、获得国家与金融 机构更多的财力支助显得尤为重要。

中国文化的对外译介与交流，有助于丰富世界文化， 维护文化的多样性。我们要在吸收和借鉴传统文化对外传 播方式的基础之上, 不断增强中国文化的内在凝聚力和国 际话语权。

文学文化无国界、优秀作品人之所向, 相信在政府的 支持下、在翻译工作者的努力下, 越来越多的中国作品能 够走出国门、走向世界。

\section{致谢}

本文为教育部留学回国人员科研启动基金课题 (项目 编号：2010120010）《基于super-function的中日被动句 机器翻译研究》的阶段性成果之一。
本文为青年教师预研究项目 一基本科研业务费 (项目 编号：2013110037）《基于文本挖掘技术的中日礼貌措辞 研究》的阶段性成果之一。

\section{参考文献}

[1] 吴望. 翻译能力建构与中译外人才培 [J], 外语学刊. 2015,1 。

［2］周明伟. 建设国际化翻译人才队伍, 推动中国文化走出去 [J].中国翻译，2014, 5。

[3］胡晓明. 如何讲述中国故事?-— “中国文化走出去” 的若 干理论与实践问题 $[\mathrm{J}]$. 华东师范大学学报 (哲学社会科学 版), 2013, 5 。

[4] 刘云虹、许钧, 文学翻译模式与中国文学对外译介一一关 于葛浩文的翻译 [J]. 外国语, 2014, 3。

[5] 祝一舒. 文化自觉与文学译介一一论许渊冲的对外译介 $[\mathrm{J}]$. 说评论, 2014.6。

[6] 徐豪. 翻译推动中国文化 “走出去” [ J J . 中国报道, 2012 (12) : 77-79。

[7] 王宁. 翻译与文华的重新定位 [J].中国翻译, 2013, 5。

［8］吴敒, 张玲. 中国文化 “走出去” 之翻译思考一一一以毕飞 宇作品在英法世界的译介与接受为例 [J]. 外国语 文, 2015, 31 (4)。

[9] 张景丰. 从中国历史上四次翻译高潮谈翻译理论的发展 $[\mathrm{J}]$. 语言与翻译, 2002, 3 。

[10］宋建清, 高友萍. 文化翻译与文化走出去. 中国出版, 2013, 9。

[11] 许多, 许钧. 中华文化典籍的对外译介与传播一一关于 《大 中华文库》的评价与思考 [J]. 外语教学理论与实践, 2015, 3。

[12] 李朝全. 中国当代文学对外译介情况 [A]. 中国作家协会, 汉 学家文学翻译国际研讨会演讲汇编 [C].2010。

[13] 吴伟. 中国文学走向世界之路 $[A]$. 中国作家协会, 汉学家文 学翻译国际研讨会演讲汇编 [C].2010。

[14] 罗福林. 中国文学翻译的挑战 [C]. 汉学家文学翻译国际研 讨会演讲汇编, 北京, 2010。

[15] 黄友义. 翻译助推中国文化走向世界. 翻译专业资格考试网, http://www. catti. net.cn/2013-01/21/content_553353. htm。

[16] 庞彦杰. 中国文化传播与西方译介受众地位的考量 [J]. 郑州航空工业管理学院学报 (社会科学版) 2015, 4。

[17] 谢天振. 译介文学作品不妨请外援[N]. 中国文化报, 2014。

[18] 李直飞. 探析中国文学出版传播模式转向一一以莫言热为 视角 $[\mathrm{J}$ ]. 中国出版, 2013, 4。

[19] 苏毅. 国家文化安全战略下的中国文化走出去战略 [J]. 暨南学报 (哲学社会科学版), 2014, 5。 